\title{
Analisis Pengaruh Sistem Akuntansi Untuk Pelaporan SAK Entitas Mikro Kecil Dan Menengah Pada Program Peningkatan Penghidupan Masyarakat Berbasis Komunitas Kota Medan (PPMK KOTA MEDAN)
}

\author{
Muhammad Arief \\ Iman Indrafana KH \\ Program Studi Akuntansi, Fakultas Ekonomi Universitas Harapan Medan \\ J1. Imam Bonjol No. 35. Medan Indonesia \\ Coresponden; muhammadariefmsi@gmail.com \\ Coresponden; indrafana@gmail.com
}

\begin{abstract}
Abstrak
Penelitian ini untuk mengetahui apakah akuntabilitas pembukuan dan laporan keuangan tujuan umum secara simultan dan parsial berpengaruh terhadap SAK mikro kecil dan menegah.Jenis penelitian ini adalah penelitian sebab akibat yang bertujuan untuk mengetahui analisis pengaruh sistem akuntansi untuk pelaporan ukm sak entitas mikro kecil dan menengah.Teknik pengambilan sampel dalam penelitian ini menggunakan purposive sampling mendapatkan jumlah sampel sebesar 70 pengusaha kecil dan menengah yang dibina oleh Program Peningkatan Penghidupan Masyarakat Bebasis Komunitas Kota Medan (PPMK Kota Medan).

Uji Simultan dan parsial mengambarkan bahwa variabelakuntabilitas pembukuan dan variabel laporan keuangan tujuan umum terhadap SAK mikro kecil dan menegah berpengaruh tidak signifikan dan variabel akuntailitas pembukuan dan laporan keuangan tujuan umum mampu menjelaskan variabel SAK mikro kecil dan menegah sebesar 4.00\% Sedangkan sisanya $96.00 \%$ di jelaskan variabel lain diluar estimasi yang diteliti saat ini.
\end{abstract}

Kata Kunci : Akuntabilitas Pembukuan, Laporan Keuangan Tujuan Umum dan SAK Mikro Kecil dan Menegah

\begin{abstract}
This research is to know whether accountability of bookkeeping and general purpose financial statements simultaneously and partially influence to small and medium-sized micro SAK. This type of research is causal research which aims to find out the analysis of the effect of the accounting system for reporting small and medium micro enterprises. The sampling technique in this study used purposive sampling to get the number of samples of 70 small and medium entrepreneurs who are guided by Community-Based Livelihood Improvement Program Medan City (PPMK Kota Medan). Simultaneous and partial tests illustrate that accountability accounting variables and variable of general purpose financial statements to small and medium-sized micro SAK have no significant effect and accounting bookkeeping variables and general purpose financial statements are able to explain small and medium-term microcredit variables of $4.00 \%$ while the remaining $96.00 \%$ are described other variables beyond the current investigated estimates.
\end{abstract}

Keywords: Accounting Accountability, General Purpose Financial Report and Micro Small and Medium SAK 
Liabilities Jurnal Pendidikan Akuntansi

e-ISSN 2620-5866

Volume 1. No.2 Agustus 2018 (168-180)

https://doi.org/10.30596/liabilities.v1i2.2229

\section{PENDAHULUAN}

UMKM (Usaha Mikro Kecil Menengah) memegang peranan yang sangat besar dalam memajukan perekonomian Indonesia.Selain sebagai salah satu alternatif lapangan kerja baru,UKM juga berperan dalam mendorong laju pertumbuhan ekonomi pasca krisis nmoneter tahun 1997 di saat perusahaanperusahaan besar mengalami kesulitan dalam mengembangkan usahanya.Saat ini,UKM telah berkontribusi besar pada pendapatan daerah maupun pendapatan Negara Indonesia.

Tujuan pembukuan adalah untuk mengungkapkan gambaran yang benar mengenai pendapatan dan pengeluaran pada akhir periode akuntansi. Tugas pembukuan dilakukan oleh pemegang buku (bookkeeper) yang bertanggung jawab untuk mencatat transaksi bisnis sehari-hari seperti keluar masuknya kas, barang yang dibeli dan dijual secara kredit, diaya yang timbul dan sebagainya secara teratur untuk kemudian mempostingnya ke dalam buku besar yang bersangkutan, dan setelah itu menyiapkan neraca saldo (Trial Balance).

Pembukuan dan pencatatan keuangan merupakan hal utama yang harus dilakukan bagi para pengusaha manapun baik pengusaha pemula maupun pengusaha tingkat atas. Bentuk pembukuan ataupun pencatatan transaksi bisnis ini dapat disesuaikan dengan tingkatan besar kecilnya suatu badan usaha. Usaha Mikro atau sekarang lebih populer dengan nama Industri Kreatif, pelaku utamanya adalah orang-orang muda. Mereka seringkali menghadapi tantangan, terutama pada saat-saat awal mendirikan usahanya. Masalah permodalan seringkali menjadi persoalan utama para pengusaha kecil pemula. Untuk itu, mereka biasanya mencari "angel investor" (istilah bagi para pengusaha yang telah sukses dan tertarik untuk membiayai industri kreatif baru meski risikonya besar). Selain angel investor, para pengusaha pemula ini juga dapat mengusahakan pinjaman lunak dari bank-bank swasta maupun pemerintah. Bank-bank tersebut biasanya memiliki dana untuk menyalurkan kredit wirausaha untuk sektor usaha mikro kecil dan menengah (UMKM). Disamping kurangnya modal, seringkali, orang-orang yang bekerja di Usaha Mikro/Industri kreatif, (yang notabene adalah anak muda) sangat minim pengetahuannya tentang pengelolaan keuangan yang baik. Mereka hanya sekedar menjalankan bisnis saja dan akan kesulitan jika menjawab pertanyaan berapa laba yang didapatkan setiap bulan atau setiap tahun ataupun berapa asset yang sekarang mereka miliki.

Untuk meningkatkan kemampuan serta pengetahuan orang-orang yang bekerjadalam Usaha Mikro atau Industri Kreatif dalam pengelolaan keuangan, maka dipandang perlu bagi dosen-dosen ekonomi, khususnya prodi akuntansi untuk memberikan pelatihankeuangan sederhana sebagai bentuk pengabdian masyarakat kepada anak-anak mudayang bekerja di industri kreatif. Kegiatan pengabdian ini ditujukan bagi mereka 
yangbekerja di Usaha Mikro/Industri Kreatif namun belum memiliki kemampuan yang cukup dalam pengelolaan keuangan. Sehingga setelah pelatihan ini output yang diharapkan adalahorang-orang yang bekerja di industri kreatif dapat menerapkan metode pengelolaan keuangan praktis yang telah diberikan dan menerapkannya dalam mengelola bisnisnya

Berdasarkan informasi yang diperoleh dari fenomena diats maka penulis berusaha membuat rangkuman perumusan masalah yang dihadapi seputar pembukuan dan pencatatan yang dapat diidentifikasikan sebagai berikut:

1. Perananpengusaha mikro kecil menengah belum mengenal akuntabilitas SAK untuk pembukuan usaha.

2. Perananpengusaha mikro kecil menengah belum memahami tujuan umum dan membuat laporan keuangan .

Adapun tujuan dari penelitian ini adalah untuk memberi pembekalan kemampuan para pengusaha mikro kecil menengah agar dapat menggunakan dan menjadikan akuntansi sebagai laporan keuangan yang simpel dalam kegiatan bisnis sehari-hari serta mengembangkan strategi pemasaran untuk masa yang akan datang sehingga dapat meningkatkan penjualan produksi dan mampu meningkatkan laba usaha mikro kecil menengah. Tujuan pelatihan ini khususnya adalah dalam hal sebagai berikut:
1. Para pengusaha mikro kecil menengah memahami Akuntabilias SAK untuk pembukuan usaha.

2. Para pengusaha mikro kecil menengah mampu memahami tujuan umum dan membuat laporan keuangan usaha.

Standar Akuntansi Keuangan Entitas Tanpa Akuntabilitas Publik (SAK ETAP) dimaksudkan untuk digunakan entitas tanpa akuntabilitas publik. Entitas tanpa akuntabilitas publik yang dimaksud adalah entitas yang :

1) Tidak memiliki akuntabilitas yang signifikan.

2) Tidak menebitkan laporan keuangan untuk tujuan umum(general purpose financial statement) bagi pengguna eksternal. Contoh pengguna eksternal adalah pemilik yang tidak terlibat langsung dalam pengelolaan usaha, kreditor, dan lembaga pemeringkat kredit.

\section{Metode Penelitian}

Jenis penelitian ini adalah penelitian sebab akibat (Causal Research) yang bertujuan untuk mengidentifikasi hubungan sebab akibat antara berbagai variabel.Dalam penelitian yang bertujuan untuk mengetahui Penerapan Akuntansi Untuk Pelaporan UKM SAK Entitas Mikro Kecil Dan Menengah.

Populasi dalam penelitian ini adalah UMKM yang ada di Kota Medan 149 kelurahan yang dibina oleh Program Peningkatan Penghidupan Masyarakat Bebasis Komunitas Kota Medan (PPMK 
Kota Medan). Penelitian ini menggunakan teknik purposive sampling, Adapun pertimbangan yang disajikan sebagai kriteria dalam pemilihan sampel adalah sebagai berikut:

a. UKM yang berada di Kecamatan Medan Timur, Medan Sunggal, Medan Barat, MedanBelawan, Medan Kota, Medan Deli, Medan Helvetia dan Medan Marelan

b. UKM melakukan Kegiatan Penjualan secara berkelanjutan

c. UKM yang telah melakukan kegiatan Akuntansi atau Pembukuan Sederhana

d. Memiliki omset Rp. 1.000.000 Rp. 5.000.000 / Bulan

e. Memilki Pinjaman Dana Bergulir Pada Program PPMK Mulai Rp. 5.000.000 - Rp. 25.000.000,-

Sehingga dari kriteria diatas maka peneliti mendapatkan jumlah sampel sebesar 70 pengusaha kecil dan menengah yang dibina oleh Program Peningkatan Penghidupan Masyarakat Bebasis Komunitas Kota Medan (PPMK Kota Medan).

Pengamatan/observasi, Dalam hal ini peneliti mengadakan pengamatan langsung ke objek penelitian.

1. Tanya jawab/wawancara dengan UKM .

2. Kuisioner, dengan menyebarkan daftar pertanyaan untuk diisi oleh UKM di PPMK Kota Medan.

Agar suatu data yang dikumpulkan dapat bermanfaat, maka harus diolahdan dianalisis terlebih dahulu sehingga dapat dijadikan dasar
pengambilankeputusan.Tujuan metode analisis data adalah untuk menginterprestasikan danmenarik kesimpulan dari sejumlah data yang terkumpul.

Teknik analisis data dalam penelitian kuantitatif menggunakan statistik. Analisis data kuantitatif terdiri dari:

\section{Uji Kualitas Data}

\section{Uji Validitas}

Untuk mendukung analisis regresi dilakukan uji validitas dan uji reliabilitas.Dalam penelitian ini digunakan untuk menguji kevalidan kuesioner.Validitas menunjukkan sejauhmana ketepatan dan kecermatan suatu alat ukur dalam melakukan fungsi alat ukurnya (Azwar, 2000).

\section{Uji Reliabilitas}

"Uji reliabiltas adalah suatu indek yang menunjukkan sejauhmana hasil suatu penelitian pengukur dapat dipercaya".(Azwar, 2000). Hasil pengukuran dapat dipercaya atau reliable hanya apabila dalam beberapakali pelaksanaan pengukuran terhadap kelompok subyek yang sama, selama aspek yang diukur dalam dari subjek memang belum berubah. Pengukuran reliabilitas dalam penelitian ini dilakukan dengan caraoneshot atau pengukuran sekali saja. Dalam hal ini pengukuran hanya sekali dan kemudian hasilnya dibandingkan dengan pertanyaan lain atau mengukur reliabilitas dengan uji statistik Cronbach Alpha (a). "Suatu variabel dikatakan 
Liabilities Jurnal Pendidikan Akuntansi

e-ISSN 2620-5866

Volume 1. No.2 Agustus 2018 (168-180)

https://doi.org/10.30596/liabilities.v1i2.2229

reliable (andal) jika nilai Cronbach Alpha (a) > 0,6". (Ghozali, 2011).

\section{Analisis Regresi Linear Berganda}

Penelitian ini menggunakan alat analisis regresi untuk menemukan atau mengetahui pengaruh variabel bebas terhadap variabel terikat dengan menggunakan program computer SPSS versi 17.

"Analisis regresi adalah studi mengenai ketergantungan variabel dependen dengan satu atau lebih variabel independen, dengan tujuan untuk mengestimasidan memprediksi rata-rata populasi atau nilai rata-rata variabel dependen berdasarkan nilai variabel independen yang diketahui'.(Ghozali, 2006).Regresi dilakukan untuk mengetahui sejauhmana variable bebas mempengaruhi variabel terikat.Pada regresi berganda terdapat satu variabel terikat dan lebih dari satu variabel bebas.Dalam penelitian ini yang menjadi variabel terikat adalah minat peserta untuk berwirausaha, sedangkan yang menjadi variabel bebas adalah Lingkungan Keluarga, Lingkungan Sekitar, Kepribadian, Motivasi, Kreativitas. Model hubungan variabel dalam penelitian ini disusun dalam persamaan atau fungsi sebagai berikut:

$$
\mathbf{Y}=\mathbf{a}+\mathbf{b}_{1} \mathbf{X}_{1}+\mathbf{b}_{2} \mathbf{X}_{2}+\mathbf{e}
$$

dimana :

Y=SAK Entitas Mikro Kecil dan Menengah

$\mathrm{X}_{1}=$ Akuntabilitas

$\mathrm{X}_{2}=$ Laporan Keuangan Tujuan Umum

$\mathrm{a}=$ Konstanta ( Nilai Y Apabila $\mathrm{X}_{1}$, Sama dengan 0) $\mathrm{b}_{1}-\mathrm{b}_{2}=$ Koefisien $\quad$ regresi $\quad$ (Nilai

Peningkatan atau Penurunan)

$\mathrm{e}=$ Error

Langkah-langkah

yang

dipergunakan dalam analisis regresi linear berganda adalah 1) koefisien determinasi; 2) Uji $\mathrm{F}$ dan 3 ) uji t. Persamaan regresi sebaiknya dilakukan di akhir analisis karena interpretasi terhadap persamaan regresi akan lebih akurat jika telah diketahui signifikansinya. Koefisien determinasi menggunakan $\underline{A d j u s t e d ~} R$ Square.

\section{Uji Asumsi Klasik}

\section{Uji Multikolonieritas}

Uji ini bertujuan untuk menguji apakah model regresi ditemukan adanya korelasi di antara variabel independen.Model regresi yang baik seharusnya tidak terjadi korelasi di antara variabel independen.Jika variabel independen saling berkorelasi, maka variabel-variabel ini tidak orthogonal."Variabel orthogonal adalah variabel independen yang nilai korelasi antar sesama variabel independen sama dengan nol".(Ghozali, 2006).

\section{Uji Heteroskedastisitas}

Uji ini bertujuan untuk menguji apakah dalam model regresi terjadiketidaksamaan variance dari residual satu pengamatan ke pengamatan yang lain. Jika variance dari residual satu pengamatan ke pengamatan lain tetap, maka disebut homoskedastisitas dan jika berbeda maka heteroskedastisitas. "Model regresi yang baik adalah yang homoskesdatisitas atau tidak terjadi 
Liabilities Jurnal Pendidikan Akuntansi

e-ISSN 2620-5866

Volume 1. No.2 Agustus 2018 (168-180)

https://doi.org/10.30596/liabilities.v1i2.2229
heteroskedastisitas.Kebanyakan data crossection mengandung situasi heteroskesdisitas karena data ini mengandung data yang mewakili berbagai ukuran".(Ghozali, 2011).

\section{Uji Normalitas}

Uji normalitas data bertujuan untuk menguji salah satu asumsi dasar analisis regresi berganda, yaitu variablevariabel independen dan dependen harus didistribusikan normal atau mendekati normal. Untuk menguji apakah data yang dikumpulkan berdistribusi normal atau tidak dapat dilakukan dengan metode sebagai berikut :

\section{Metode grafik}

Metode grafik yang handal untuk menguji normalitas data adalah dengan melihat normal probability plot, sehingga hampir semua aplikasi komputer statistik menyediakan fasilitas ini.Normal probability plot adalah membandingkan distribusi kumulatif data yang sesungguhnya dengan distribusi kumulatif dari distribusi normal (hypotheeical distribution).

"Proses uji normalitas data dilakukan dengan memperhatikan penyebaran data (titik) pada Norma $P$ -
Plot of Regression Standardized dari variable terikat". (Santoso, 2000), di mana :

1) Jika data menyebar di sekitar garis diagonal, maka model regresi memenuhi asumsi normalitas.

2) Jika data menyebar jauh dari diagonal atau mengikuti garis diagonal, maka model regresi tidak memenuhi asumsi normalitas.

\section{Metode Statistik}

Uji statistik sederhana yang sering digunakan untuk menguji asumsi normalitas adalah dengan menggunakan uji normalitas dari Kolmogorov Smirnov.Metode pengujian normal tidaknya distribusi data dilakukan dengan melihat nilai signifikansi variabel, jika signifikan lebih besar dari alpha 5\% maka menunjukkan distribusi data normal.

\section{HASIL DAN PEMBAHASAN \\ Hasil}

\section{Analisis Kuantitatif}

Uji Validitas

Adapun hasil analisis regresi dilakukan uji validitas pada variabel SAK mikro kecil dan menegah dengan variabel akuntabilitas pembukuan adalah sebagai berikut :

\section{Tabel Uji Validitas I}

KMO and Bartlett's Test

\begin{tabular}{|ll|r|}
\hline & Kaiser-Meyer-Olkin Measure of Sampling Adequacy. & .554 \\
Bartlett's Test of & Approx. Chi-Square & 473.906 \\
Sphericity & Df & 190 \\
& Sig. & .000 \\
\hline
\end{tabular}

Sumber : data diolah, 2017 
Liabilities Jurnal Pendidikan Akuntansi

e-ISSN 2620-5866

Volume 1. No.2 Agustus 2018 (168-180)

https://doi.org/10.30596/liabilities.v1i2.2229

Adapun hasil dari tampilan output SPSS di atas menunjukan bahwa nilai $K M O$ and Bartlett's Test $=0.554$ Sehingga dapat dilakukan analisis faktor. Begitu juga dengan nilai Bartllet's test dengan Chi-square $=473.906$ dan signifikansi pada 0.000, maka dapat disimpulakan bahwa uji validitas sesuai ketentuan yang berlaku dan dapat dilanjutkan.

Sedangkan hasil korelasi antara variabel SAK mikro kecil dan menegah dengan laporan keuangan tujuan umum adapun nilai dari uji dengan confirmatory factor analysis (CFA) dapat dilihat nilainya sebagai berikut:

\section{Tabel Uji Validitas II}

KMO and Bartlett's Test

\begin{tabular}{|ll|r|}
\hline & Kaiser-Meyer-Olkin Measure of Sampling & .582 \\
& Adequacy. & \\
Bartlett's Test of & Approx. Chi-Square & 509.951 \\
Sphericity & Df & 190 \\
& Sig. & .000 \\
\hline
\end{tabular}

Sumber : data diolah, 2017

Hasil dari tampilan menunjukan bahwa nilai $\mathrm{KMO}=0.582$ Sehingga dapat dilakukan analisis faktor. Begitu juga dengan nilai Bartllet's test dengan Chisquare $=509.951$ dan signifikansi pada 0.000, maka dapat disimpulakan bahwa uji validitas dengan confirmatory factor analysis (CFA) sehingga dapat disimpulkan data tersebut valid.

\section{Uji Reabilitas}

Uji reabilitas berguna untuk menganalisis jawaban terhadap indikator ini dari konstruk SAK mikro kecil dan menegah, akuntailitas keuangan, dan laporan keuangan tujauan umum apakah dapat dikatakan reabel atau tidak, dapat kita lihat dari ui SPSS hasilnya dibawah ini :

Tabel Uji Reabilitas Variabel SAK Mikro kecil dan Menegah

Reliability Statistics

\begin{tabular}{|r|rr|}
\hline Cronbach's Alpha & Nof Items \\
\hline & .692 & 10 \\
\hline
\end{tabular}

Sumber : data diolah, 2017

Tabel Uji Reabilitas Variabel Akuntabilitas pembukuan

Reliability Statistics 
Liabilities Jurnal Pendidikan Akuntansi

e-ISSN 2620-5866

Volume 1. No.2 Agustus 2018 (168-180)

https://doi.org/10.30596/liabilities.v1i2.2229

Reliability Statistics

\begin{tabular}{|r|rr|}
\hline Cronbach's Alpha & N of Items \\
\hline & .644 & 10 \\
\hline
\end{tabular}

Sumber : data diolah, 2017

Tabel Uji Reabilitas Variabel Laporan Keuangan Tujuan Umum

Reliability Statistics

\begin{tabular}{|r|rr|}
\hline Cronbach's Alpha & Nof Items \\
\hline .646 & 10 \\
\hline
\end{tabular}

Sumber : data diolah, 2017

Menurut kreteria Nunnally (1960) suatu konstrak bisa dikatakan realiabel jika memberikan nilai Cronbach Alpha > 0.60 dari hasil SPSS di atas variabel SAK Mikro kecil dan Menegah menunjukan nilai $=0.692$, variabel Akuntailitas pembukuan dengan nilai $=$ 0.644, Laporan Keuangan Tujuan Umum $=0.646$ dari hasil semua nilai dari Cronbach Alpha menunjukkan diatas
0.60 maka dapat dikatakan jawaban dari respoden tersebut adalah realiabel.

\section{Uji Asumsi Klasik}

Uji Normalitas

Uji satistik untuk menguji normalitas residual pada penelitian ini mengunakan uji statistik non parametik One-Sample Kolmogorov-Smirnov Test dengan hasil sebagai berikut :

Tabel Uji Normalitas

One-Sample Kolmogorov-Smirnov Test

\begin{tabular}{|c|c|c|}
\hline & & Unstandardized Residual \\
\hline \multirow{3}{*}{ Normal Parameters ${ }^{a, b}$} & $N$ & 70 \\
\hline & Mean & .0000000 \\
\hline & Std. Deviation & 2.19771649 \\
\hline \multirow[t]{5}{*}{ Most Extreme Differences } & Absolute & .118 \\
\hline & Positive & .118 \\
\hline & Negative & -.071 \\
\hline & Kolmogorov-Smirnov Z & .986 \\
\hline & Asymp. Sig. (2-tailed) & .285 \\
\hline
\end{tabular}

a. Test distribution is Normal.

b. Calculated from data.

Sumber : data diolah, 2017 
Liabilities Jurnal Pendidikan Akuntansi

e-ISSN 2620-5866

Volume 1. No.2 Agustus 2018 (168-180)

https://doi.org/10.30596/liabilities.v1i2.2229

Dari hasil uji stastistik diatas diperoleh nilai Kolmogorov-Smirnov $Z$ sebesar 0.986 dan Asymp. Sig $=0.285>$ 0.05 sehingga dapat disimpulkan data residual berdistribusi normal dan model regresi yang dilakukan memenuhi asumsi normalitas.

Uji Multikolinearitas

Uji multikolinearitas dalam penelitian ini bertujuan untuk menguji apakah model regresi ditemukan adanya kolerasi antara variabel pada model regresi yang baik seharusnya tidak terjadi kolerasi antar variabel independen. Nilai umunya digunakan menunjukkan adanya multikolinearitas apabila tolerance $\geq 0.10$ atau sama dengan nilai VIF $\leq 10$, hasilnya dapat dilihat dalam tabel dibawah ini:

Tabel Uji Multikolinearitas

Coefficients $^{a}$

\begin{tabular}{|ll|r|r|}
\hline \multirow{2}{*}{ Model } & \multicolumn{2}{|c|}{ Collinearity Statistics } \\
\cline { 3 - 4 } & $\mathrm{X}_{1}$ & Tolerance & \multicolumn{2}{|c|}{ VIF } \\
\hline 1 & $\mathrm{X}_{2}$ & .848 & 1.179 \\
& & .848 & 1.179 \\
\hline
\end{tabular}

a. Dependent Variable: Y

Sumber : data diolah, 2017

Dari hasil uji statistik nilai di atas menunjukkan ada variabel yang menunjukkan nilai tolerance lebih besar dari 0.10 dan VIF (Variance Inflation Factor) lebih kecil dari 10.dengan kata lain dapat disimpulkan tidak ada lagi terjadi multikolinearitas antara variabel independen dalam model regresi analisis ini.

\section{Uji Heteroskedastisitas}

Uji ini bertujuan apakah dalam regresi ini ketidaksamaan variance dari satu residual satu pengamatan kepengamatan yang lain tetap maka disebut homokedasitas jika berbeda disebut heteroskedastisitas.

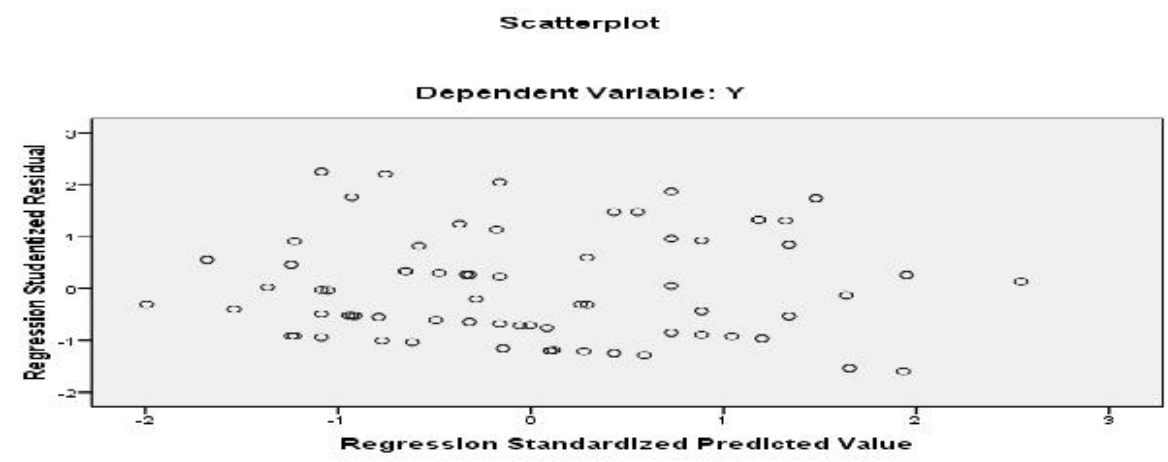

Gambar Grafik Scatterplot 
Liabilities Jurnal Pendidikan Akuntansi

e-ISSN 2620-5866

Volume 1. No.2 Agustus 2018 (168-180)

https://doi.org/10.30596/liabilities.v1i2.2229

Gambar grafik di atas menunjukkan bahwa titik menyebar secara acak serta menyebar baik diatas maupun dibawah angka 0 pada sumbu $\mathrm{Y}$ tidak membentuk pola teratur yang menidentifikasikan tidak terjadi heteroskedastisitas.

Uji Autokorelasi

Uji autokorelasi bertujuan menguji apakah model regresi ada kolerasi antara kesalahan pengganggu pada periode $\mathrm{t}$ dengan kesalahan penggangu dengan periode $\mathrm{t}-1$ (sebelumnya).

\section{Tabel Autokolerasi}

Model Summaryb

\begin{tabular}{|c|c|c|c|c|c|c|}
\hline \multirow[b]{2}{*}{ Model } & \multicolumn{5}{|c|}{ Change Statistics } & \\
\hline & $\begin{array}{c}R \text { Square } \\
\text { Change }\end{array}$ & F Change & $d f 1$ & $d f 2$ & $\begin{array}{c}\text { Sig. F } \\
\text { Change }\end{array}$ & Durbin-Watson \\
\hline 1 & .040 & 1.408 & 2 & 67 & .252 & 1.682 \\
\hline
\end{tabular}

b. Dependent Variable: Y

Sumber : data diolah, 2017

Nilai Durbin-Watson diatas menunjukkan $=1.682$ dibandingkan dengan nilai durbin-watson (DW) dengan jumlah $\mathrm{n}=70$, jumlah variabel independen $(\mathrm{k})=2$ dan nilai $\mathrm{du}=1.671$. Oleh nilai $\mathrm{DW}=1.682>\mathrm{du}=1.729 \mathrm{atau}$ kurang dari $4-\mathrm{du}(1.671)=2.329$ dengan ini maka dapat disimpulkan tidak terdapat autokorelasi.

Tabel Uji F

Model Summaryb

\begin{tabular}{|l|r|r|r|r|r|}
\hline \multirow{3}{*}{ Model } & \multicolumn{5}{|c|}{ Change Statistics } \\
\cline { 2 - 7 } & $R$ Square Change & F Change & df1 & \multicolumn{1}{|c|}{$d f 2$} & Sig. F Change \\
\hline 1 & .040 & 1.408 & 2 & 67 & .252 \\
\hline
\end{tabular}

b. Dependent Variable: Y

Sumber : data diolah, 2017

Dari tabel $\mathrm{F}_{\text {hitung }}=1.408<\mathrm{F}_{\text {tabei }}=$ berpengaruh signifikan secara simultan 3.13 dengan nilai sig $0.252>0.05$ berarti terhadap SAK mikro kecil dan menegah. variabel akuntailitas pembukuan dan Uji Koefesien secara Parsial (Uji t) laporan keuangan tujuan umum tidak 
Liabilities Jurnal Pendidikan Akuntansi

e-ISSN 2620-5866

Volume 1. No.2 Agustus 2018 (168-180)

https://doi.org/10.30596/liabilities.v1i2.2229

Tabel Uji t

Coefficients $^{a}$

\begin{tabular}{|c|c|c|c|c|c|c|}
\hline \multirow{2}{*}{\multicolumn{2}{|c|}{ Model }} & \multicolumn{2}{|c|}{ Unstandardized Coefficients } & \multirow{2}{*}{$\begin{array}{c}\begin{array}{c}\text { Standardized } \\
\text { Coefficients }\end{array} \\
\text { Beta }\end{array}$} & \multirow[b]{2}{*}{$t$} & \multirow[b]{2}{*}{ Sig. } \\
\hline & & $B$ & Std. Error & & & \\
\hline \multirow[t]{3}{*}{1} & (Constant) & 26.070 & 3.907 & & 6.674 & .000 \\
\hline & $\mathrm{X}_{1}$ & .071 & .104 & .088 & .678 & .500 \\
\hline & $\mathrm{X}_{2}$ & .134 & .116 & .149 & 1.150 & .254 \\
\hline
\end{tabular}

a. Dependent Variable: $\mathrm{Y}$

Sumber : data diolah, 2017

Pada variabel akuntailitas pembukuan $\left(\mathrm{X}_{1}\right)$ nilai $\mathrm{t}_{\text {hitung }}$ sebesar0.678 $<\mathrm{t}_{\text {tabel }} 1.666$ maka variabel akuntabilitas pembukuan dengan kata lain maka terdapat pengaruh yang tidak signifikan terhadap SAK mikro kecil dan menegah.

tujuan umum $\left(\mathrm{X}_{2}\right)$ niai $\mathrm{t}_{\text {hitung }}$ sebesar1.150 < $\mathrm{t}_{\text {tabel }} 1.666$ maka pada variabel laporan keuangan tujuan umum terdapat pengaruh yang tidak signifikan terhadap SAK mikro kecil dan menegah.

Dan pada variabel laporan keuangan

Pengujian Ketepatan Perkiraan $\left(\mathrm{R}^{2}\right)$

Tabel Uji $\mathbf{R}^{2}$

Model Summary ${ }^{b}$

\begin{tabular}{|l|r|r|r|r|}
\hline \multirow{2}{*}{ Model } & \multicolumn{5}{|c|}{} & \multicolumn{4}{|c|}{$R$} & $R$ Square & Adjusted $R$ Square & Std. Error of the Estimate \\
\hline 1 & $.201^{\mathrm{a}}$ & .040 & .012 & 2.23028 \\
\hline
\end{tabular}

a. Predictors: (Constant), $X_{2}, X_{1}$

b. Dependent Variable: $Y$

Sumber : data diolah, 2017

Nilai $R^{2}=0.04$ artinya variabel akuntailitas pembukuan dan laporan keuangan tujuan umum mampu menjelaskan variabel SAK mikro kecil dan menegah seesar $4.00 \%$ Sedangkan sisanya $96.00 \%$ di jelaskan variabel lain diluar estimasi yang diteliti saat ini.

\section{PEMBAHASAN}

Dari pengujian di atas didapat persamaan sebagai berikut:

$$
\begin{array}{cr}
Y=26,070 \\
\text { Nilai } & \text { 0,071 } \\
\left(\mathbf{X}_{1}\right)+\mathbf{0 , 1 3 4}\left(\mathbf{X}_{2}\right) \\
\text { konstanta }
\end{array}
$$
tanpaakuntabilitas pembukuan $\left(\mathrm{X}_{1}\right)$ dan laporan keuangan tujuan $\operatorname{umum}\left(\mathrm{X}_{2}\right)$ sebesar 26,070. Nilai di atas menunjukan nilai estimasi dimana koefisien 
akuntabilitas sebesar 0,071artinya Apabila nilai akuntabilitas pembukuan meningkat satu persen maka nilai SAK mikro kecil dan menengah akan naik sebesar tuuh koma satu persen. Bila standar akuntansi keuangan diterapkan terhadap pengusaha kecil dan menengah akan berdampak menaikan kualitas lapooran pembukuan. Maka dalam hal ini pengusaha harus terus meningkatkan kualitas ppengetahuan tentang SAK mikro kecil dan menengah sehingga bukan hanya bermanfaat bagi pengusaha kecil dan menengah tetapi bermanfaat juga bagi pihak eksternal baik pihak Bank yang berperan aktif dalam pengembangan usaha kecil dan menengah dan pemerintah sebagai pemilik program peningkatan penghidupan masyarakat yang berbasis komunitas.

Koefisien laporan keuangan dengan tujuan umum sebesar 0.134 mengambarkan bahwa apabila laporan keuangan tujuan umum meningkat sebesar satu persen maka nilai SAK mikro kecil dan menengah akan naik sebesar tiga elas koma empat persenn. Jadi Semakin besarlaporan keuangan berguna untuk tujuan umum, maka pengusaha akan mendapatkan informasi yang akurat tentang perputaran usaha yang sedang dijalanin dan dapat menjadi rencana dalam pengembangan usaha kecil dan menengah.

\section{SIMPULAN DAN SARAN}

\section{Simpulan}

1.Uji Simultan mengambarkan bahwa variabelakuntabilitas pembukuan dan variabel laporan keuangan tujuan umum terhadap SAK mikro kecil dan menegah berpengaruh tidak signifikan secara simultadan parsial

2.Variabel variabel akuntailitas pembukuan dan laporan keuangan tujuan umum mampu menjelaskan variabel SAK mikro kecil dan menegah sebesar $4.00 \%$ Sedangkan sisanya $96.00 \%$ di jelaskan variabel lain diluar estimasi yang diteliti saat ini.

\section{Saran}

1.Salah satu akuntabilitas pembukuan tersebut adalah pemahaman tentang laporan keuangan dalam hal ini program peningkatan penghidupan masyarakat (PPMK Kota Medan) haus lebih bekerja keras lagi dalam mensosialisasikan pemahaman pembukuan dan melakukan pelatihan tentang laporan keuangan sesuai dngan SAK mikro kecil dan menengah.

2.Pengusaha kecil dan menegah disarankan membuat laporan keuangan dengan tujuan umum bukan hanya berguna bagi si pengusaha kecil dan menengah juga bisa berguna bagi pihak investor, perbankan dan pemerintah dalam programnya meningkatkan usaha kecil dan menengah.

3.Peneliti selanjutnya sangat disarankan menambah variabelvariabel yang lain yang berhubugan lansung terhadap intergritas laporan keuangan 
Liabilities Jurnal Pendidikan Akuntansi

e-ISSN 2620-5866

Volume 1. No.2 Agustus 2018 (168-180)

https://doi.org/10.30596/liabilities.v1i2.2229

\section{DAFTAR PUSTAKA}

Erlina, Sri Mulyani, 2007, Metodologi Penelitian Bisnis Untuk Akuntansi dan Manajemen Cetakan Pertama USU Press, Medan.

Ernawati Sri, Asyikin Jumirin, Sari Octavia 2016, Penerapan Sistem Akuntansi Dasar pada Usaha Kecil Menengah di kota Banjarmasin, Jurnal Penelitian Ilmu Ekonomi WIGA Vol. 6 No. 2, September 2016

Ghozali, Imam. 2006." Aplikasi Analisis

Multivariate dengan Menggunakan Program SPSS". Universitas Diponegoro, Semarang.

Hasanuh, Nanu2012, Akuntansi Dasar (Teori \& Praktik), Penerbit Mitra Wacana Media.

Irawan, 2018, Pengenalan Komputer Untuk Orang Awam, Maxikom

Nuh, Muhammad 2013, Accounting Principles, Penerbit Fajar Cahaya Jakarta.

Rahmawati, 2015, Bisnis Usaha Keci Menengah, Penerbit Bukuekuilibria.

Rianti, Ayu Agus 2016, Pembukuan

Sederhana Usaha Dagang \& Jasa, Laskar Aksara.

SaragihFitriani, Surikayanti, 2015

Analisis Penerapan Akuntansi dan Kesesuaiannya Dengan SAK ETAP

Pada UKM Medan Perjuangan, Seminar Nasional Ekonomi Manajemen Dan Akuntansi (Snema) Fakultas Ekonomi Universitas Negeri Padang Snema-2015 PadangIndonesia. ISBN: 978-602-17129-5-5 Soemarso, 2014, Akuntansi Suatu Pengantar, Penerbit Salemba Empat.
Tambunan, Tulus 2017, Usaha Mikro, Kecil, dan Menengah, Penerbit Ghalia Indonesia. 